\title{
Potential Power of the Pyramidal Structure V: Seasonal Changes in the Periodicity of Diurnal Variation of Biosensors Caused by Entanglement Due to Pyramid Effects
}

\author{
Osamu Takagi ${ }^{1}$, Masamichi Sakamoto², Kimiko Kawano${ }^{1}$, Mikio Yamamoto ${ }^{1}$ \\ ${ }^{1}$ International Research Institute (IRI), Chiba, Japan; ${ }^{2}$ Aquavision Academy, Chiba, Japan \\ Correspondence to: Osamu Takagi, takagi@a-iri.org \\ Keywords: Pyramid, Potential Power, Entanglement, Meditation, Biosensor, Cucumis sativus, Gas, Psi Index \\ Received: December 8, $2021 \quad$ Accepted: December 25, $2021 \quad$ Published: December 28, 2021
}

Copyright $\odot 2021$ by author(s) and Scientific Research Publishing Inc.

This work is licensed under the Creative Commons Attribution International License (CC BY 4.0).

http://creativecommons.org/licenses/by/4.0/

\section{(c) (i) Open Access}

\section{ABSTRACT}

Since October 2007, we have been conducting rigorous scientific experiments to elucidate the so-called "pyramid power". The experiments use a pyramidal structure (PS). In order to detect the PS effects, a biosensor is made from cucumber fruit sections and the released volatile components are analyzed as gas concentration. We reported the phenomenon of entanglement between biosensors in part IV of the paper series, Potential Power of the Pyramidal Structure. The entanglement affected the gas concentration of the biosensors $8 \mathrm{~m}$ away, but not the biosensors at the PS apex. In this paper, we report another characteristic of the entanglement. The results and our conclusion are as follows. Result 1: The periodicity of diurnal variation in gas concentration changed with entanglement. Result 2: As a result of analyzing the gas concentration data separately for the four seasons of winter, spring, summer, and autumn, the seasonal dependence of the periodicity of diurnal variation due to entanglement was clarified. Conclusion: We reaffirmed the existence of the entanglement between biosensors due to the pyramid effects by a phenomenon different from Part IV of the paper series, Potential Power of the Pyramidal Structure. We expect that our research results will be widely accepted in the future and will become the foundation for a new research field in science, with a wide range of applications.

\section{INTRODUCTION}

Research on the so-called "pyramid power" began in the late 1930s [1]. However, since pyramid power has been regarded as having no scientific basis, there have been very few scientific research papers published in academic journals regarding pyramid power [2, 3]. Since October 2007, we have been conducting 
rigorous scientific experiments and analyses on the unexplained force of a pyramidal structure (PS), that is, the pyramid power. So far, we have reported the research results as ten original papers [4-13], three comprehensive reports [14-16], and one book chapter [17]. Their important research results are summarized below.

1) From the test subject meditating in the PS, we experimentally demonstrated the pyramid effects affecting the biosensors at the PS apex [4].

2) We discovered a delayed pyramid effect after the test subject meditated in the PS. The pyramid effects could be detected for more than a dozen days after meditation [5].

3) By identifying the conditions for the pyramid effects to occur, we concluded that the PS was an energy converter [6].

4) We found that the PS captured the unconsciousness of the test subject more than $6 \mathrm{~km}$ away and affected the biosensors at the PS apex [9].

5 ) We experimentally revealed the existence of a potential power, pyramid power, of the PS [10].

6) Due to the potential power of the PS, we showed that the pyramid effects on the biosensors placed in two layers on the PS apex were greater in the upper layer than in the lower layer [11].

7) We discovered a seasonally fluctuating pyramid effects and a non-seasonally fluctuating pyramid effects [12].

8) We found entanglement between biosensors due to the pyramid effects [13].

9) We showed that the diurnal variation of the gas concentration emitted from the biosensors was periodic $[7,8]$.

From these experimental results, we have classified the pyramid effects by the PS into the i) the effects produced by the power (potential power, pyramid power) of the PS itself; and ii) the pyramid effects caused by the influence of the test subject meditating inside the PS. Regarding (i), we have clarified four results so far. 1) The potential power of the PS affected the biosensors placed at the PS apex. Specifically, we divided the experimental data $(n=468)$ obtained throughout the year into two periods, using the spring equinox and the autumn equinox, and the pyramid effects (psi index) of each period were compared. As a result, $\mathrm{p}=6.0 \times 10^{-3}$, a statistically significant result, was obtained (Welch's t-test, two-tails, the same applies to the p value hereafter) [10]. 2) The pyramid effects on the biosensors placed in two layers at the PS apex were different between the lower and upper layers. The psi index $\Psi$, which represents the pyramid effects, was negative, $\Psi=-3.01$, for the lower biosensors and positive, $\Psi=5.52$, for the upper biosensors. Comparing the pyramid effects in the lower and upper layers, we obtained $\mathrm{p}=4.0 \times 10^{-7}$ which was statistically highly significant [11]. 3) As a result of analyzing the annual data by dividing them according to winter, spring, summer, and autumn, there were two types of pyramid effects, one that changed seasonally and the other that did not change seasonally. When comparing winter and summer, for the type that changed with the season, $\mathrm{p}=1.8 \times 10^{-3}$ was obtained which was statistically significant [12]. 4) When pyramid effects on the biosensors were analyzed by the gas concentration only, without using the psi index, we found entanglement between biosensors, which was not observed when using the psi index (the present discussion section gives the reason for this). Specifically, the biosensors placed at the PS apex, i.e. experimental samples, were affected by the potential power of the PS, and as a result, the gas concentration of the biosensors at the calibration control point, i.e. control samples, were affected. We also clarified that the magnitude of the influence of entanglement changed depending on the season [13].

The purpose of this paper is to report another phenomenon caused by the entanglement between biosensors due to the pyramid effects. In previous papers $[7,8]$, we reported that the diurnal variation of the gas concentration emitted from the biosensors placed at the calibration control point shows periodicity. We also clarified that there are two types of diurnal fluctuations in gas concentration, one cycle and four cycles per 24 hours, respectively. In the analysis results of this paper, the periodicity of the diurnal variation of the gas concentration was reproduced, and there was another periodicity. Furthermore, we found that the periodicity of diurnal fluctuations in gas concentration was changed by the entanglement due to the pyramid effects. And, as a result of analyzing the data by dividing it into four seasons, we clarified that the periodicity of diurnal variation due to entanglement depends on the season. 


\section{EXPERIMENT AND ANALYSIS METHOD}

\subsection{Pyramidal Structure: PS}

Figure 1(a) shows the PS used. It is a square pyramid with a height of $107 \mathrm{~cm}$, a ridgeline length of $170 \mathrm{~cm}$ and a base length of $188 \mathrm{~cm}$. The tilt angle between the bottom and the side of the PS is $49.1^{\circ}$ and the base is raised $73 \mathrm{~cm}$ from the floor. The frame was made of four aluminum pipes $(2 \mathrm{~cm}$ diameter, 0.36 $\mathrm{cm}$ thick pipe wall), the top ends of which were connected. The bottom ends of each pipe were placed at the four corners of a square $(188 \mathrm{~cm}$ on each side) made with four aluminum $\mathrm{L}$ angles. The four aluminum pipes were not electrically connected to the $\mathrm{L}$ angles, and they were not electrically grounded. The four sides of the PS were made of $1 \mathrm{~cm}$ thick polystyrene boards, which were not grounded. A $0.03 \mathrm{~cm}$ thick aluminum plate with a Sierpinski triangle fractal pattern is attached to the four sides of the PS. The four aluminum pipes were electrically connected to the aluminum plates on all the sides, but since the pipes were not grounded, the aluminum plates were not either. Inside the PS, a transparent acrylic $(0.5 \mathrm{~cm}$ thick) dome ( $85 \mathrm{~cm}$ diameter, $66.5 \mathrm{~cm}$ high) with a spherical shell shape was placed. The lower portion of the sphere had been removed where the diameter of the sphere cross-section was $68.1 \mathrm{~cm}$. The dome was sitting on a wooden square board $(99 \mathrm{~cm} \times 99 \mathrm{~cm}, 3 \mathrm{~cm}$ thick) with a $70 \mathrm{~cm}$ diameter hole in the center that allowed the test subject to insert his head and upper body into the dome space. The bottom surface of the board was held at a height of $85 \mathrm{~cm}$ by four tripods. The dome was designed in such a way that the test subject's voice resonated inside. At the top of the PS, a Faraday cage for electrostatic shielding of the biosensors is placed. Since the PS shown in Figure 1(a) was installed in the laboratory on November 24, 2009, the experiments have been continued without changing the installation state in any way. The laboratory is located at 140.1040 degrees east longitude and 35.6399 degrees north latitude.

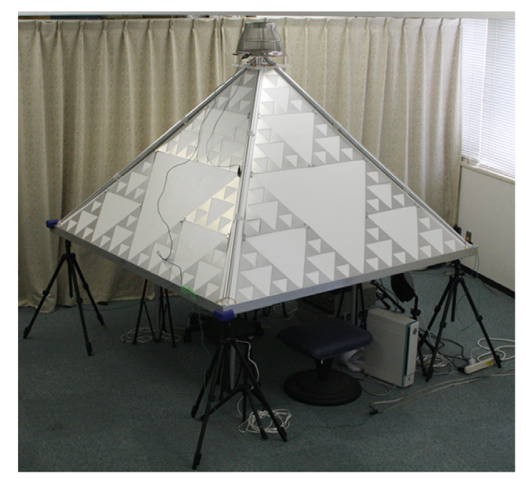

(a)

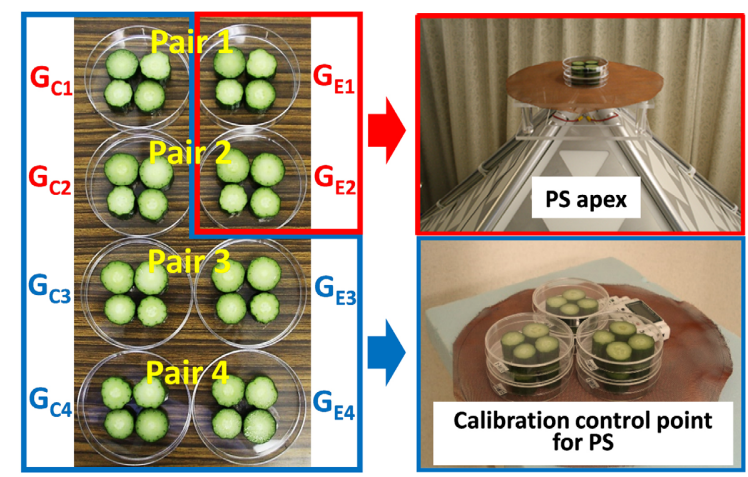

(b)

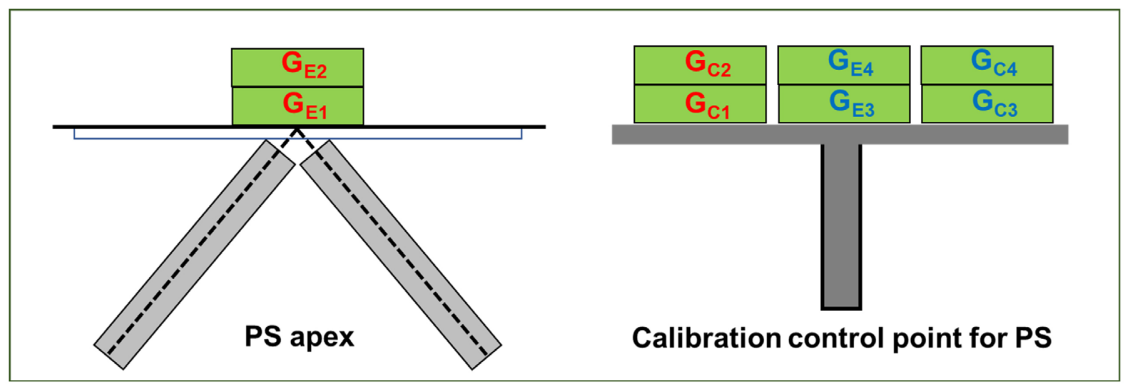

(c)

Figure 1. The pyramidal structure (PS) used and installation conditions of the biosensors. (a) The PS. (b) Left: Biosensors prepared for SCAT application. Right: Placement of samples at the PS apex and calibration control point. (c) Schematic diagrams showing side views of placement of samples at the PS apex and calibration control point. 


\subsection{Biosensors}

We used biosensors made by cutting the cucumber fruit, Cucumis sativus, to verify the pyramid effects of the PS. The biosensors were placed at the PS apex and the calibration control point for 30 minutes, and the volatile components were measured, as gas concentration released from the affected biosensors at each location. As shown in Figure 1(b), uniform biosensors were prepared from four cucumbers, and four sets of pairs were prepared so that the simultaneous calibration technique, SCAT, could be applied [18]. The experimental sample $G_{E}$ and the control sample $G_{C}$ were pairs, the upper surface of the $G_{E}$ and $G_{C}$ cucumber sections placed on the Petri dishes was the same cut surface, but the direction of the axes was different. The direction of the upper surface of the cucumber sections placed on the Petri dish was defined as the direction from the lower surface in contact with the Petri dish to the upper surface. At this time, the upper surface of the section placed on the $\mathrm{G}_{\mathrm{E}}$ was in the same direction as the growth axis of the cucumber. In addition, the upper surface of the section placed on the $G_{C}$ was in the direction opposite to the growth axis. The growth axis of the cucumber was the direction from the vine side to the flower side of the cucumber fruit. We reported previously that the gas concentration differs depending on the direction of the cut surface, and $G_{\mathrm{E}}<\mathrm{G}_{\mathrm{C}}$ [8]. As shown in Figure $1(\mathrm{c}), \mathrm{G}_{\mathrm{E} 1}$ and $\mathrm{G}_{\mathrm{E} 2}$ were placed in two layers at the PS apex, and $\mathrm{G}_{\mathrm{C} 1}, \mathrm{G}_{\mathrm{C} 2}, \mathrm{G}_{\mathrm{E} 3}, \mathrm{G}_{\mathrm{E} 4}, \mathrm{G}_{\mathrm{C} 3}, \mathrm{G}_{\mathrm{C} 4}$ were placed in two layers at the calibration control point $8.0 \mathrm{~m}$ away from the PS. The difference in height between the two layers was $2.0 \mathrm{~cm}$. After 30 minutes, the biosensors were stored in a closed container with a capacity of 2.2 liters for 24 - 48 hours after removing the lid of the Petri dish. After storage, the gas concentration was measured using a gas detector tube and an ethyl acetate detector tube (141 L: Gastech, Japan) and gas sampling pump (GV-100: Gastech). We prepared eight biosensors from four cucumbers in one experiment, while another experiment used another four cucumbers to prepare the biosensors. We have used more than 15,000 cucumbers in previous experiments.

\subsection{Periodic Approximation Curve of Gas Concentration}

In previous papers $[7,8]$, we clarified that the diurnal variation of the gas concentration emitted from the biosensors placed at the calibration control point shows periodicity. In this paper, we attempted to analyze not only the biosensors placed at the calibration control point but also the periodicity of the diurnal variation of the biosensors placed at the PS apex. In order to verify whether the diurnal variation of gas concentration has periodicity, we considered a periodic approximation curve as shown in Equation (1).

$$
y=a+b \sin (2 \pi x N)+c \cos (2 \pi x N)=a+\sqrt{b^{2}+c^{2}} \sin (2 \pi x N+\phi), \phi=\arcsin \left(\frac{c}{\sqrt{b^{2}+c^{2}}}\right) .
$$

Here, $y$ represents the gas concentration. $x$ represents the time, and the time from 0:00 to 24:00 is represented by the value corresponding to the numerical value 0 to 1 . The reason for this is that we assumed that the gas concentration value and the phase of the periodic curve change so as to match every 24 hours. $N$ is the number of cycles per 24 hours, and $N$ is an integer value from 1 to 24 . Equation (1) represents a periodic approximation curve with 1 cycle per 24 hours when $N=1$, and an approximation curve with 24 cycles per 24 hours when $N=24$. The $a, b, c$ are constants and $\pi$ is pi (3.1415). For each value of $N$ from 1 to 24 , we found a periodic approximation curve of the gas concentration and determined the constants $a, b$, and $c$. After that, the correlation coefficient between the gas concentration and the periodic approximation curve was calculated. As a result, if the correlation coefficient was 0.2 or more and the significance of the correlation coefficient was satisfied, we could show that the diurnal variation of the gas concentration changes periodically.

\section{EXPERIMENTAL AND ANALYSIS RESULTS}

Figure 2(a) plots results of experiments conducted between 2010 and 2017 excluding the influence of the test subject, and the total number of data $\mathrm{n}=468$. The gas concentrations $\left(\mathrm{G}_{\mathrm{E} 1}+\mathrm{G}_{\mathrm{E} 2}\right) / 2$ and $\left(\mathrm{G}_{\mathrm{C} 1}+\right.$ $\left.\mathrm{G}_{\mathrm{C} 2}\right) / 2$ were plotted with the horizontal axis as time, from 0:00 to 24:00. The time shown here refers to the 


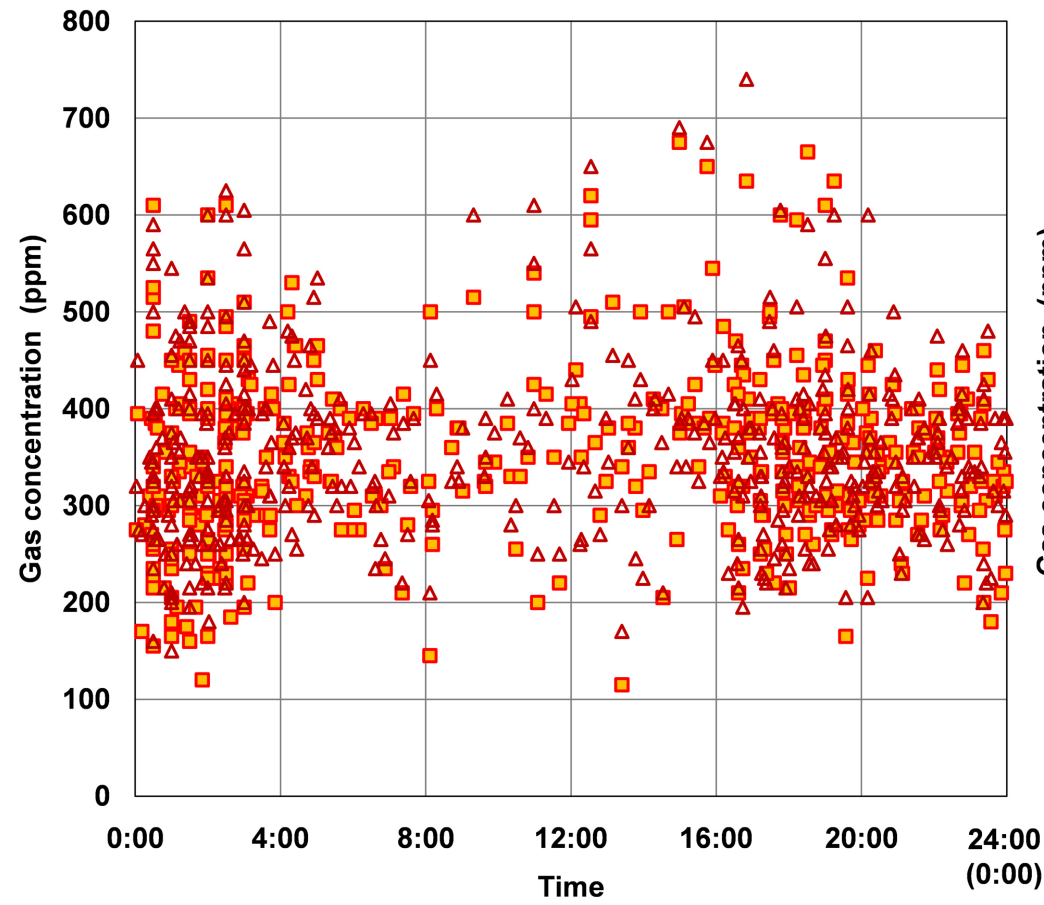

(a)

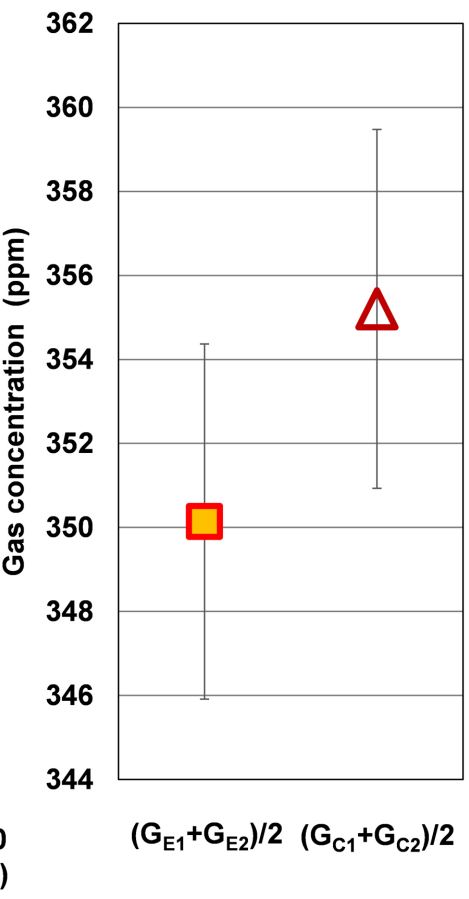

(b)

Figure 2. Concentration of volatile components released from the biosensors, as gas concentration. (a) Distribution of gas concentration between 0:00 and 24:00, the number of data $n=468$. The filled red square: $\left(G_{\mathrm{E} 1}+\mathrm{G}_{\mathrm{E} 2}\right) / 2$. The open dark red triangle: $\left(\mathrm{G}_{\mathrm{C} 1}+\mathrm{G}_{\mathrm{C} 2}\right) / 2$. (b) Average gas concentration of $\left(\mathrm{G}_{\mathrm{E} 1}+\mathrm{G}_{\mathrm{E} 2}\right) / 2$ and $\left(\mathrm{G}_{\mathrm{C} 1}+\mathrm{G}_{\mathrm{C} 2}\right) / 2$. The error bar is the standard error, $\mathrm{SE}$.

time when the biosensors were placed at the PS apex and the calibration control point. Each filled red square is the average gas concentration $\left(\mathrm{G}_{\mathrm{E} 1}+\mathrm{G}_{\mathrm{E} 2}\right) / 2$ of the experimental samples placed in two layers at the PS apex, and each open dark red triangle is the average gas concentration $\left(\mathrm{G}_{\mathrm{C} 1}+\mathrm{G}_{\mathrm{C} 2}\right) / 2$ of the control samples placed in two layers at the calibration control point. Figure 2(b) gives the average values of all the data of $\left(\mathrm{G}_{\mathrm{E} 1}+\mathrm{G}_{\mathrm{E} 2}\right) / 2$ and $\left(\mathrm{G}_{\mathrm{C} 1}+\mathrm{G}_{\mathrm{C} 2}\right) / 2$. No significant difference was detected when comparing the averages of all the data $(p=0.400)$. However, the tendency of $\left(\mathrm{G}_{\mathrm{E} 1}+\mathrm{G}_{\mathrm{E} 2}\right) / 2<\left(\mathrm{G}_{\mathrm{C} 1}+\mathrm{G}_{\mathrm{C} 2}\right) / 2$ was seen.

Figure 3(a) plots experimental results excluding the influence of the test subject as in Figure 2(a) and it shows the gas concentrations $\left(\mathrm{G}_{\mathrm{E} 3}+\mathrm{G}_{\mathrm{E} 4}\right) / 2$ and $\left(\mathrm{G}_{\mathrm{C} 3}+\mathrm{G}_{\mathrm{C} 4}\right) / 2$. Each open blue square is the average gas concentration $\left(\mathrm{G}_{\mathrm{E} 3}+\mathrm{G}_{\mathrm{E} 4}\right) / 2$ of the experimental samples placed in two layers at the calibration control point, and each open dark blue triangle is the average gas concentration $\left(\mathrm{G}_{\mathrm{C} 3}+\mathrm{G}_{\mathrm{C} 4}\right) / 2$ of the control samples placed in two layers at the calibration control point. Figure 3(b) gives the average values of all the data of $\left(G_{\mathrm{E} 3}+G_{\mathrm{E} 4}\right) / 2$ and $\left(\mathrm{G}_{\mathrm{C} 3}+\mathrm{G}_{\mathrm{C} 4}\right) / 2$. No significant difference was detected when comparing the averages of all the data $(p=0.378)$. However, the tendency of $\left(G_{E 3}+G_{E 4}\right) / 2<\left(G_{C 3}+G_{C 4}\right) / 2$ was seen. The tendency for $\left(G_{\mathrm{E} 3}+G_{\mathrm{E} 4}\right) / 2<\left(G_{\mathrm{C} 3}+G_{\mathrm{C} 4}\right) / 2$ in the experimental sample and the control sample placed at the calibration control point was reported before [8] and there was $5 \%$ statistical significance $(\mathrm{p}=0.049, \mathrm{n}=1817)$. We considered the reason why the gas concentration differs between the experimental samples and the control samples to be that the direction of the cut surface of the cucumber was different. We expected that the reason why the significant difference could not be detected in Figure 3(b) was that the number of data was small. From the results of Figure 2(b), when comparing the experimental samples at the PS apex and the control samples at the calibration control point, we found that the gas concentration of the control samples was higher than that of the experimental samples. This meant that there was no significant difference between $\left(\mathrm{G}_{\mathrm{E} 1}+\mathrm{G}_{\mathrm{E} 2}\right) / 2$ and $\left(\mathrm{G}_{\mathrm{E} 3}+\mathrm{G}_{\mathrm{E} 4}\right) / 2$ even if the potential power of the PS affected the experimental 


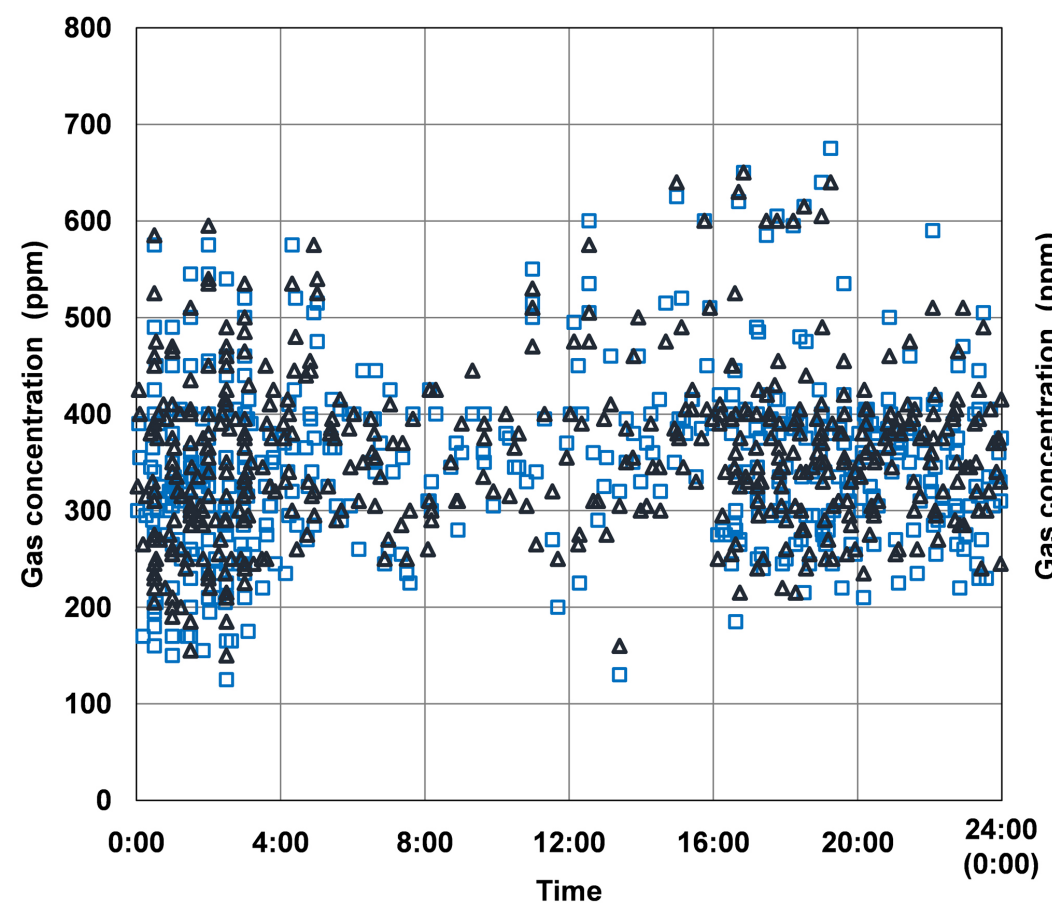

(a)

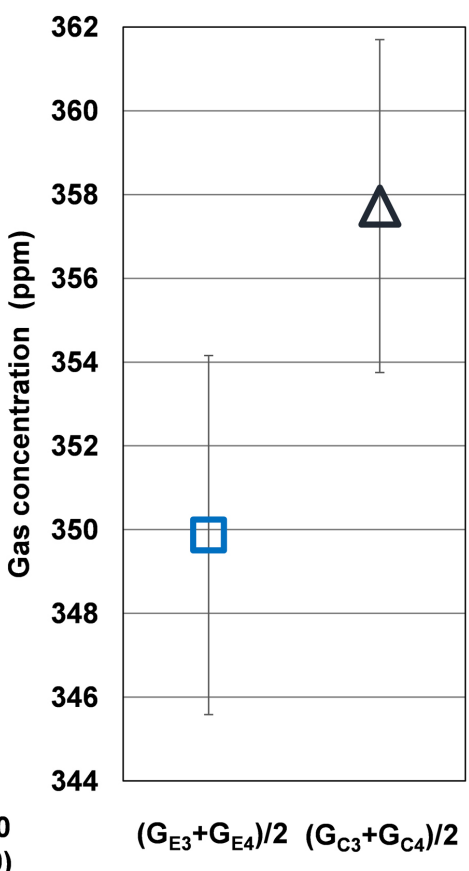

(b)

Figure 3. Concentration of volatile components released from the biosensors, as gas concentration. (a) Distribution of gas concentration between 0:00 and 24:00, the number of data $n=468$. The open blue square: $\left(G_{\mathrm{E} 3}+\mathrm{G}_{\mathrm{E} 4}\right) / 2$. The open dark blue triangle: $\left(\mathrm{G}_{\mathrm{C} 3}+\mathrm{G}_{\mathrm{C} 4}\right) / 2$. (b) Average gas concentration of $\left(G_{\mathrm{E} 3}+\mathrm{G}_{\mathrm{E} 4}\right) / 2$ and $\left(\mathrm{G}_{\mathrm{C} 3}+\mathrm{G}_{\mathrm{C} 4}\right) / 2$. The error bar is the standard error, $\mathrm{SE}$.

samples at the PS apex. However, in our earlier paper [11], we clarified that the change in gas concentration was qualitatively different between the experimental samples at the PS apex and the experimental samples at the calibration control point when the lower and upper stages stacked in two layers were treated separately.

Figure 4 replots the average gas concentrations shown in Figure 2(b) and Figure 3(b) together, where each filled red square is $\left(G_{\mathrm{E} 1}+G_{\mathrm{E} 2}\right) / 2$, each open blue square is $\left(\mathrm{G}_{\mathrm{E} 3}+\mathrm{G}_{\mathrm{E} 4}\right) / 2$, each open dark red triangle is $\left(\mathrm{G}_{\mathrm{C} 1}+\mathrm{G}_{\mathrm{C} 2}\right) / 2$, and each open dark blue triangle is the result of $\left(\mathrm{G}_{\mathrm{C} 3}+\mathrm{G}_{\mathrm{C} 4}\right) / 2$. The squares are experimental samples and the triangles, control samples. No significant difference could be detected between the average values of the four points, but we saw that the gas concentrations of the control samples were higher than those of the experimental samples. In addition, the average values of $\left(\mathrm{G}_{\mathrm{E} 1}+\mathrm{G}_{\mathrm{E} 2}\right) / 2$ and $\left(G_{E 3}+G_{E 4}\right) / 2$ of the experimental sample were almost the same. From this, we found that the pyramid effects of the PS apex could not be detected by simply comparing the average gas concentrations of the experimental samples of the PS apex and the experimental samples of the calibration control point.

Figure 5 shows the correlation coefficient between the gas concentrations shown in Figure 2(a) and Figure 3(a) and the periodic approximation curve of the gas concentration calculated using Equation (1). In this paper, in order to analyze the periodicity of the diurnal variation of the gas concentration emitted from the biosensors of the PS apex and the calibration control point, we considered only the case where the number of cycles per 24 hours is an integer. The horizontal axis of Figures 5(a)-(d) is the number of cycles, $\mathrm{N}$ per 24 hours, and the value of $\mathrm{N}$ is an integer from 1 to 24 . When $\mathrm{N}=1$, the correlation coefficient between the periodic approximation curve with one cycle of 24 hours and the gas concentration is shown and when $\mathrm{N}=24$, the correlation coefficient between the periodic approximation curve with one cycle of 1 hour and the gas concentration is shown. It is possible to analyze when $\mathrm{N}$ is 25 or more, but 


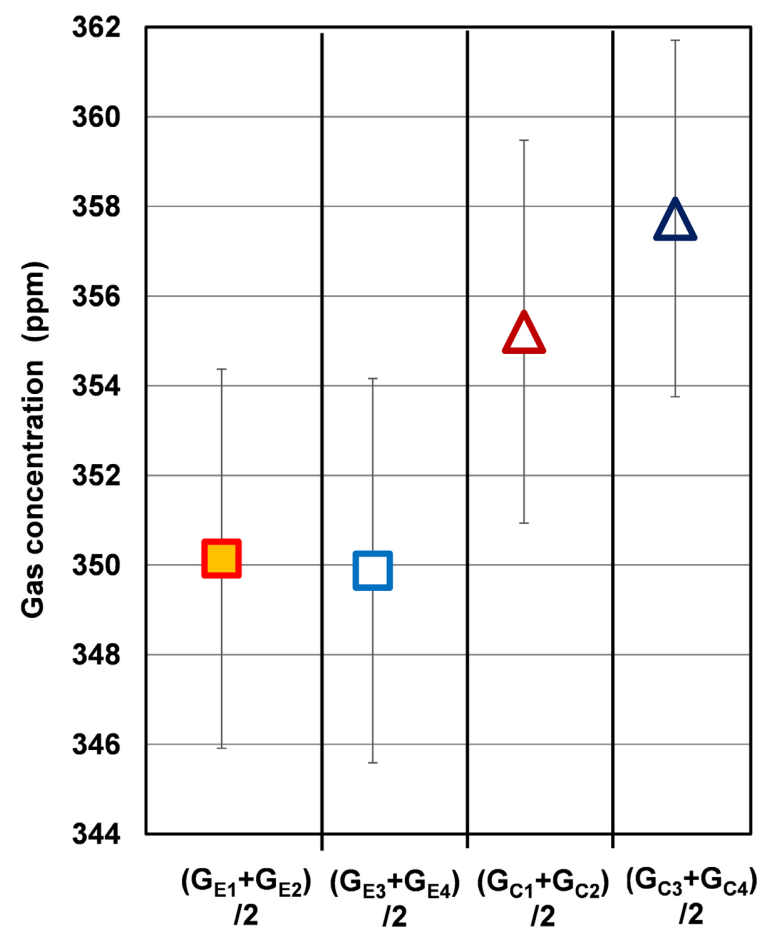

Figure 4. Average gas concentrations emitted from the biosensors. The error bar is the standard error, $\mathrm{SE}$.

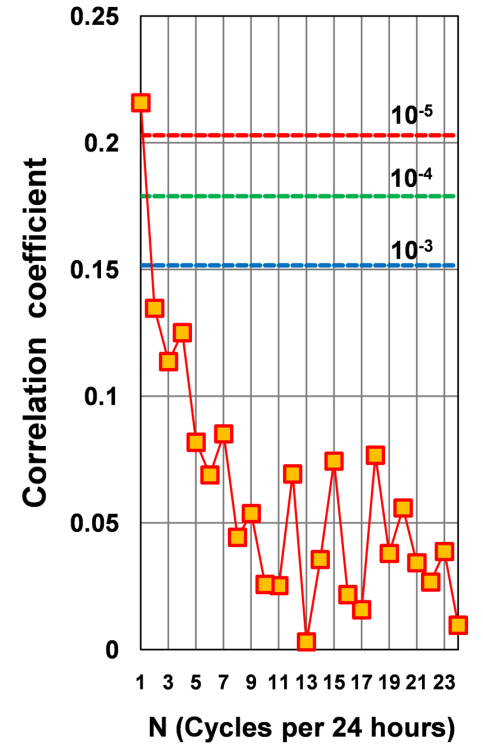

(a)

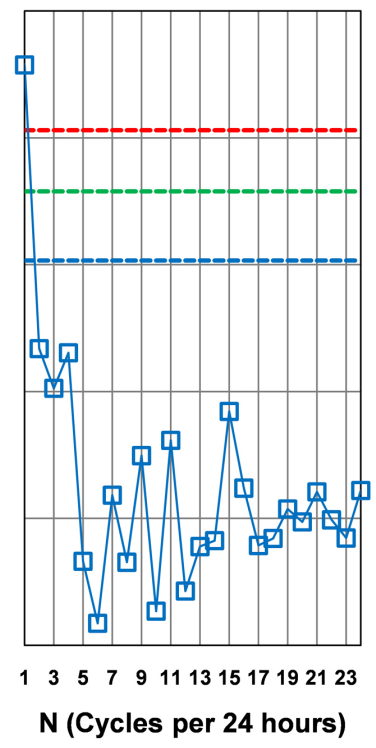

(b)

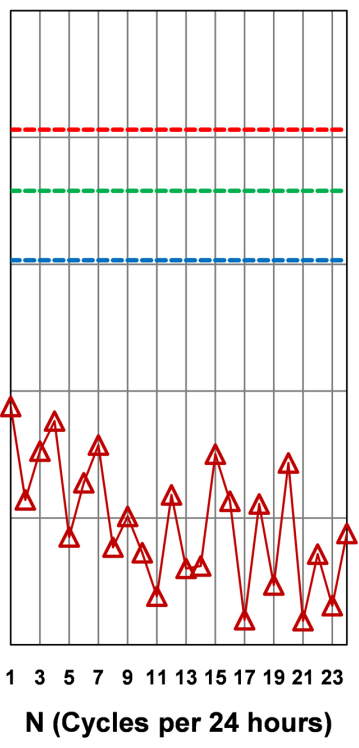

(c)

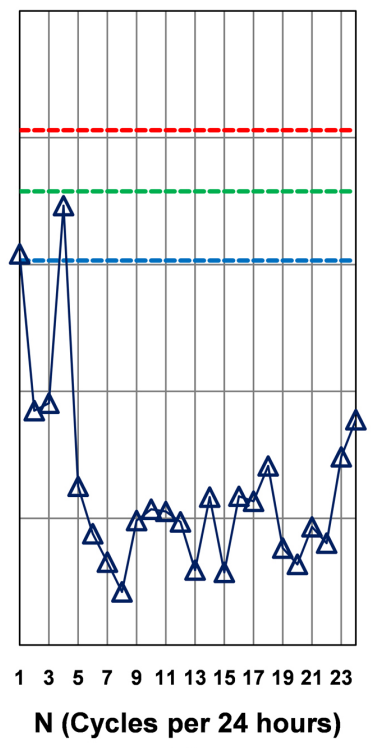

(d)

Figure 5. Correlation coefficient between gas concentration and periodic approximation curve. (a) $\left(G_{\mathrm{E} 1}+\mathrm{G}_{\mathrm{E} 2}\right) / 2$. (b) $\left(\mathrm{G}_{\mathrm{E} 3}+\mathrm{G}_{\mathrm{E} 4}\right) / 2$. (c) $\left(\mathrm{G}_{\mathrm{C} 1}+\mathrm{G}_{\mathrm{C} 2}\right) / 2$. (d) $\left(\mathrm{G}_{\mathrm{C} 3}+\mathrm{G}_{\mathrm{C} 4}\right) / 2$. The horizontal axis $\mathrm{N}$ is the number of cycles per 24 hours. The broken lines in the figure are the degree of significance of the correlation coefficient: when the number of data was $n=468$, the dashed red value was 0.203 and $p=$ $10^{-5}$, the dashed green value was 0.178 and $\mathrm{p}=10^{-4}$, and the dashed blue value was 0.152 and $\mathrm{p}=$ $10^{-3}$. 
since the time resolution in our experimental method was about 30 minutes, the analysis was performed here with the number of cycles $\mathrm{N}$ per 24 hours as an integer of 1 to 24 . The broken lines in the figure show the degree of significance of the correlation coefficient depending on the number of data. When the number of data was $\mathrm{n}=468$, the dashed red value was 0.203 and $\mathrm{p}=10^{-5}$, the dashed green value was 0.178 and $\mathrm{p}=10^{-4}$, and the dashed blue value was 0.152 and $\mathrm{p}=10^{-3}$. In addition, it is generally considered that there is a correlation if the absolute value of the correlation coefficient is 0.2 or more.

Five items could be understood from Figure 5. 1) In Figure 5(a), Figure 5(b) and Figure 5(d), when $\mathrm{N}=1$, the $\mathrm{p}$-value was $\mathrm{p}<10^{-3}$, but in Figure 5(c), $\left.\mathrm{p}>10^{-3} .2\right)$ In Figure 5(a) and Figure 5(b) of the experimental samples, the $\mathrm{N}$ dependence of the correlation coefficient was relatively similar. From this, in the experimental samples, no significant difference was observed in the periodicity of the diurnal variation between the PS apex and the calibration control point. 3) In Figure 5(a), Figure 5(b) and Figure 5(d), it seemed that there was a certain peak even at $N=4$, but in Figure $5(\mathrm{c})$, there was no peak at $N=4$. 4) Since Figure 5(b) and Figure 5(d) show pairs placed at the calibration control points, the $\mathrm{N}$ dependence of the correlation coefficient was considered to be the same, but there were differences. We considered the reason to be that the orientation of the axis of the cut surface of the biosensors was different. 5) The peaks for $\mathrm{N}=1,4$ in Figure 5(b) and Figure 5(d) corresponded to the results reported previously [8]. However, in [8], all experimental data for the period between 2010 and 2017 were analyzed. These data included both the results of the experiment excluding the influence of the test subject and the results of the experiment not excluding this influence. From (1)-(5), we concluded that only Figure 5(c), which was the results of analyzing $\left(\mathrm{G}_{\mathrm{C} 1}+\mathrm{G}_{\mathrm{C} 2}\right) / 2$ in Figure 5, exhibited a different change from the others. We suspected this was because $\left(\mathrm{G}_{\mathrm{C} 1}+\mathrm{G}_{\mathrm{C} 2}\right) / 2$ is the pair to $\left(\mathrm{G}_{\mathrm{E} 1}+\mathrm{G}_{\mathrm{E} 2}\right) / 2$, and $\left(\mathrm{G}_{\mathrm{E} 1}+\mathrm{G}_{\mathrm{E} 2}\right) / 2$ was affected by the potential power of the PS. We pointed out the existence of an entanglement between the pair $\left(\mathrm{G}_{\mathrm{E} 1}+\mathrm{G}_{\mathrm{E} 2}\right) / 2$ and $\left(\mathrm{G}_{\mathrm{C} 1}+\mathrm{G}_{\mathrm{C} 2}\right) / 2$ in an earlier paper [13]. We believed from the present results that this entanglement affected the periodicity of diurnal fluctuations in gas concentration.

Next, the annual data $(n=468)$ were analyzed by dividing them into the four seasons of winter, spring, summer, and autumn. Then, the relationship between seasonal changes in periodic diurnal fluctuations and entanglement was examined in detail. Table 1 summarizes the classification of the four seasons and the number of data for each.

Figures 6-9 show the correlation coefficient between the gas concentration in each season and the periodic approximation curve.

Table 1. Definitions for the classifications of winter, spring, summer and autumn and the number of data.

\begin{tabular}{|c|c|c|c|c|}
\hline Classification & Season & Period & & $\begin{array}{l}\text { Number } \\
\text { of data }\end{array}$ \\
\hline WTR & winter & $\begin{array}{l}\text { from the winter solstice to the day } \\
\text { before the spring equinox }\end{array}$ & from $12 / 22$ to $3 / 20$ & 84 \\
\hline SPR & spring & $\begin{array}{l}\text { from the spring equinox to the day } \\
\text { before the summer solstice }\end{array}$ & from $3 / 21$ to $6 / 20$ & 108 \\
\hline SMR & summer & $\begin{array}{l}\text { from the summer solstice to the day } \\
\text { before the autumn equinox }\end{array}$ & from $6 / 21$ to $9 / 22$ & 144 \\
\hline AUT & autumn & $\begin{array}{l}\text { from the autumn equinox to the day } \\
\text { before the winter solstice }\end{array}$ & from $9 / 23$ to $12 / 21$ & 132 \\
\hline
\end{tabular}




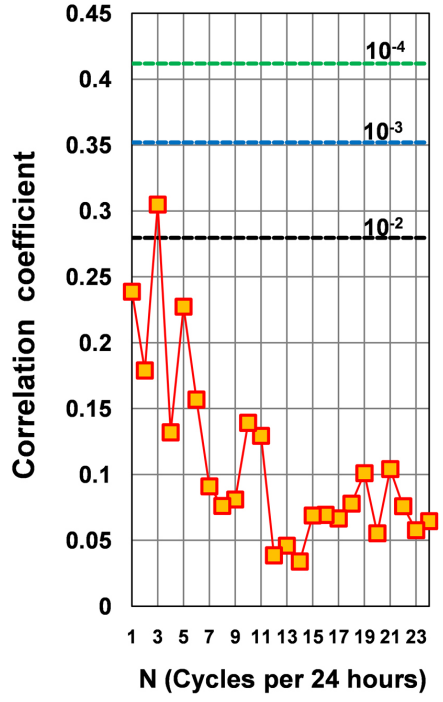

(a)

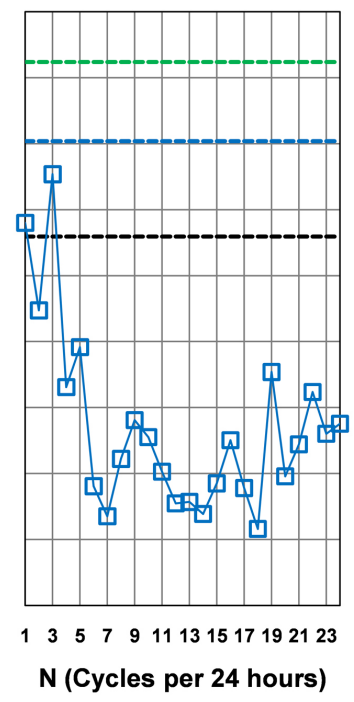

(b)

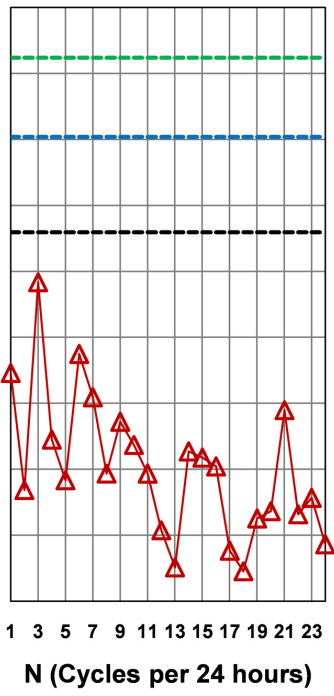

(c)

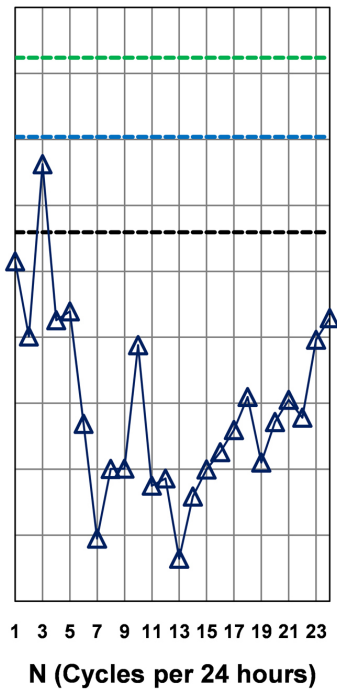

(d)

Figure 6. Correlation coefficient between gas concentration and periodic approximation curve in winter. (a) $\left(G_{\mathrm{E} 1}+\mathrm{G}_{\mathrm{E} 2}\right) / 2$. (b) $\left(\mathrm{G}_{\mathrm{E} 3}+\mathrm{G}_{\mathrm{E} 4}\right) / 2$. (c) $\left(\mathrm{G}_{\mathrm{C} 1}+\mathrm{G}_{\mathrm{C} 2}\right) / 2$. (d) $\left(\mathrm{G}_{\mathrm{C} 3}+\mathrm{G}_{\mathrm{C} 4}\right) / 2$. The horizontal axis $\mathrm{N}$ is the number of cycles per 24 hours. The broken lines in the figure are the degree of significance of the correlation coefficient: when the number of data was $n=84$, the dashed green value was 0.412 and $\mathrm{p}=10^{-4}$, the dashed blue value was 0.352 and $\mathrm{p}=10^{-3}$, and the dashed black value was 0.279 and $\mathrm{p}=10^{-2}$.

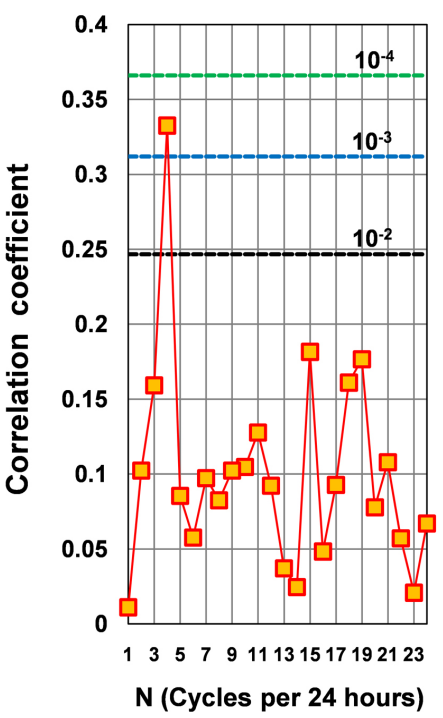

(a)



(b)

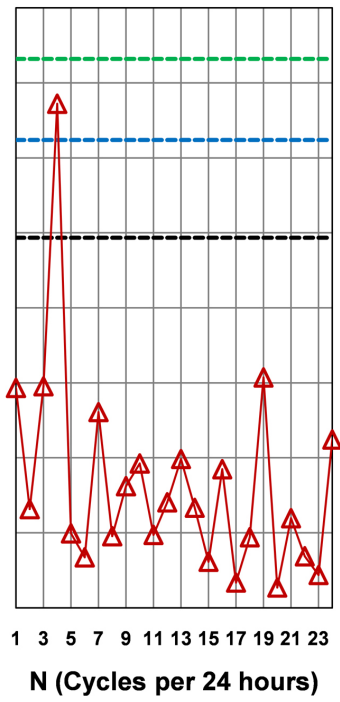

(c)

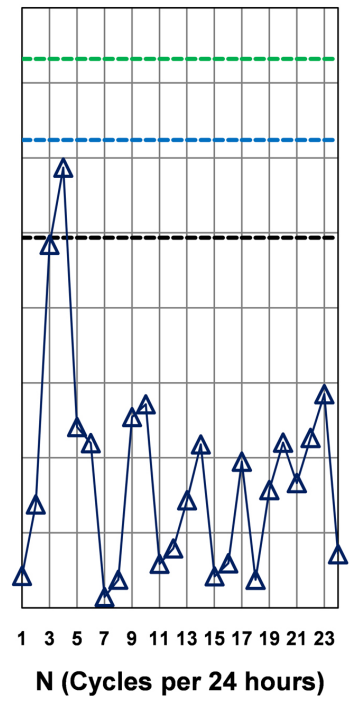

(d)

Figure 7. Correlation coefficient between gas concentration and periodic approximation curve in spring. (a) $\left(G_{\mathrm{E} 1}+\mathrm{G}_{\mathrm{E} 2}\right) / 2$. (b) $\left(\mathrm{G}_{\mathrm{E} 3}+\mathrm{G}_{\mathrm{E} 4}\right) / 2$. (c) $\left(\mathrm{G}_{\mathrm{C} 1}+\mathrm{G}_{\mathrm{C} 2}\right) / 2$. (d) $\left(\mathrm{G}_{\mathrm{C} 3}+\mathrm{G}_{\mathrm{C} 4}\right) / 2$. The horizontal axis $\mathrm{N}$ is the number of cycles per 24 hours. The broken lines in the figure are the degree of significance of the correlation coefficient: when the number of data was $n=108$, the dashed green value was 0.366 and $\mathrm{p}=10^{-4}$, the dashed blue value was 0.312 and $\mathrm{p}=10^{-3}$, and the dashed black value was 0.247 and $\mathrm{p}=10^{-2}$. 


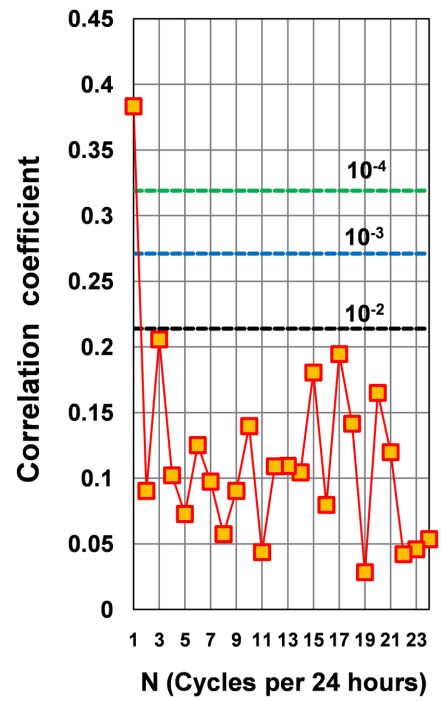

(a)

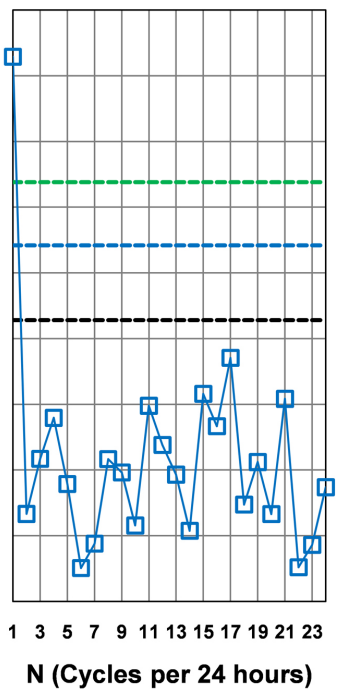

(b)

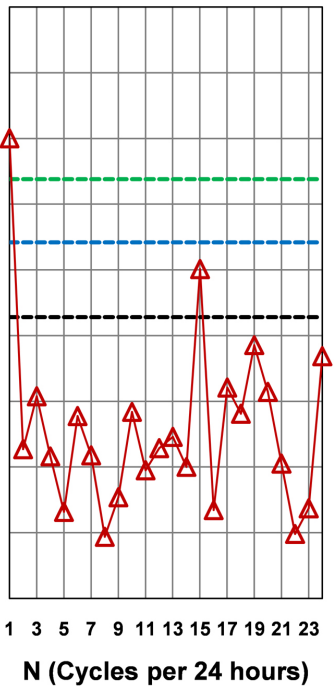

(c)

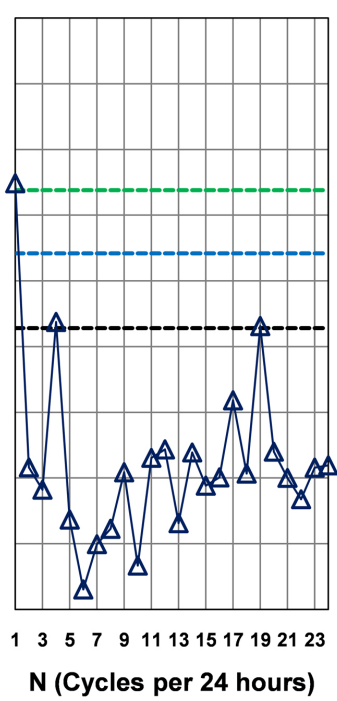

(d)

Figure 8. Correlation coefficient between gas concentration and periodic approximation curve in summer. (a) $\left(\mathrm{G}_{\mathrm{E} 1}+\mathrm{G}_{\mathrm{E} 2}\right) / 2$. (b) $\left(\mathrm{G}_{\mathrm{E} 3}+\mathrm{G}_{\mathrm{E} 4}\right) / 2$. (c) $\left(\mathrm{G}_{\mathrm{C} 1}+\mathrm{G}_{\mathrm{C} 2}\right) / 2$. (d) $\left(\mathrm{G}_{\mathrm{C} 3}+\mathrm{G}_{\mathrm{C} 4}\right) / 2$. The horizontal axis $\mathrm{N}$ is the number of cycles per 24 hours. The broken lines in the figure are the degree of significance of the correlation coefficient: when the number of data was $n=144$, the dashed green value was 0.319 and $\mathrm{p}=10^{-4}$, the dashed blue value was 0.271 and $\mathrm{p}=10^{-3}$, and the dashed black value was 0.214 and $\mathrm{p}=10^{-2}$.

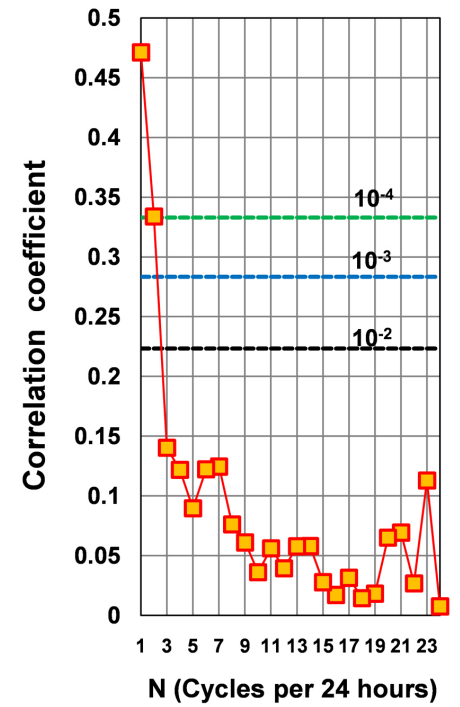

(a)

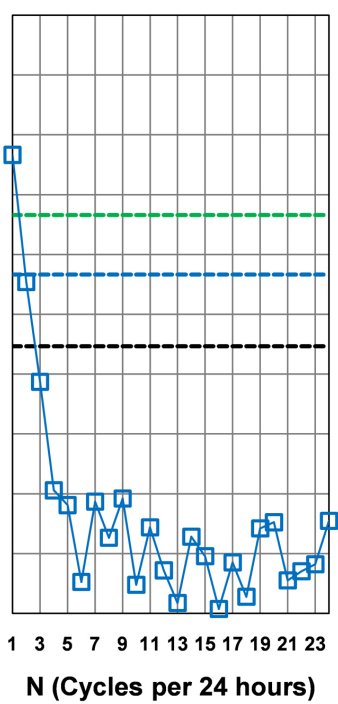

(b)

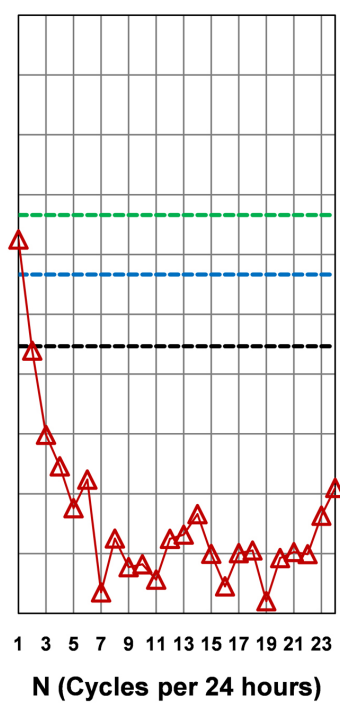

(c)

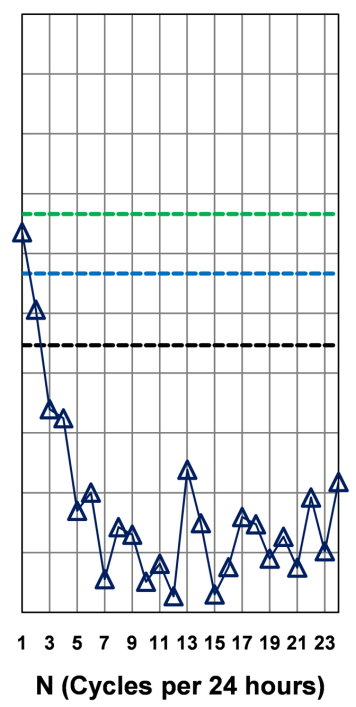

(d)

Figure 9. Correlation coefficient between gas concentration and periodic approximation curve in autumn. (a) $\left(\mathrm{G}_{\mathrm{E} 1}+\mathrm{G}_{\mathrm{E} 2}\right) / 2$. (b) $\left(\mathrm{G}_{\mathrm{E} 3}+\mathrm{G}_{\mathrm{E} 4}\right) / 2$. (c) $\left(\mathrm{G}_{\mathrm{C} 1}+\mathrm{G}_{\mathrm{C} 2}\right) / 2$. (d) $\left(\mathrm{G}_{\mathrm{C} 3}+\mathrm{G}_{\mathrm{C} 4}\right) / 2$. The horizontal axis $\mathrm{N}$ is the number of cycles per 24 hours. The broken lines in the figure are the degree of significance of the correlation coefficient: when the number of data was $n=132$, the dashed green value was 0.333 and $\mathrm{p}=10^{-4}$, the dashed blue value was 0.283 and $\mathrm{p}=10^{-3}$, and the dashed black value was 0.223 and $p=10^{-2}$. 
Figures 6(a)-(d) show the correlation coefficient between the gas concentration of the winter data (n $=84$ ) and the periodic approximation curve. The horizontal axis is the number of cycles $\mathrm{N}$ per 24 hours and is an integer from 1 to 24 . Figures $6(\mathrm{a})-(\mathrm{d})$ are the results of $\left(\mathrm{G}_{\mathrm{E} 1}+\mathrm{G}_{\mathrm{E} 2}\right) / 2,\left(\mathrm{G}_{\mathrm{E} 3}+\mathrm{G}_{\mathrm{E} 4}\right) / 2,\left(\mathrm{G}_{\mathrm{C} 1}+\right.$ $\left.\mathrm{G}_{\mathrm{C} 2}\right) / 2$, and $\left(\mathrm{G}_{\mathrm{C} 3}+\mathrm{G}_{\mathrm{C} 4}\right) / 2$ respectively. The dashed line in the figure is the degree of significance of the correlation coefficient. When the number of data was $\mathrm{n}=84$, the dashed green value was 0.412 and $\mathrm{p}=$ $10^{-4}$, the dashed blue value was 0.352 and $\mathrm{p}=10^{-3}$, and the dashed black value was 0.279 and $\mathrm{p}=10^{-2}$. In all cases, we saw that the correlation coefficient had the maximum value when $\mathrm{N}=3$. Next, when $\mathrm{N}=1$, the correlation coefficient was large; however, only in Figure 6(c) was the correlation coefficient less than 0.2 , which was different from the others.

Figures 7(a)-(d) show the correlation coefficient between the gas concentration of the spring data ( $n$ $=108)$ and the periodic approximation curve. Figures $7(\mathrm{a})-(\mathrm{d})$ are the results of $\left(\mathrm{G}_{\mathrm{E} 1}+\mathrm{G}_{\mathrm{E} 2}\right) / 2,\left(\mathrm{G}_{\mathrm{E} 3}+\right.$ $\left.\mathrm{G}_{\mathrm{E} 4}\right) / 2,\left(\mathrm{G}_{\mathrm{C} 1}+\mathrm{G}_{\mathrm{C} 2}\right) / 2,\left(\mathrm{G}_{\mathrm{C} 3}+\mathrm{G}_{\mathrm{C} 4}\right) / 2$ respectively. The dashed line in the figure is the degree of significance of the correlation coefficient. When the number of data was $n=108$, the dashed green value was 0.366 and $\mathrm{p}=10^{-4}$, the dashed blue value was 0.312 and $\mathrm{p}=10^{-3}$, and the dashed black value was 0.247 and $\mathrm{p}=10^{-2}$. In all cases, we saw that the correlation coefficient had the maximum value when $\mathrm{N}=4$. Next, the change from $\mathrm{N}=1$ to $\mathrm{N}=3$ was qualitatively different only in Figure 7 (c).

Figures 8(a)-(d) show the correlation coefficient between the gas concentration of the summer data $(\mathrm{n}=144)$ and the periodic approximation curve. Figures $8(\mathrm{a})-(\mathrm{d})$ are the results of $\left(\mathrm{G}_{\mathrm{E} 1}+\mathrm{G}_{\mathrm{E} 2}\right) / 2,\left(\mathrm{G}_{\mathrm{E} 3}+\right.$ $\left.\mathrm{G}_{\mathrm{E} 4}\right) / 2,\left(\mathrm{G}_{\mathrm{C} 1}+\mathrm{G}_{\mathrm{C} 2}\right) / 2,\left(\mathrm{G}_{\mathrm{C} 3}+\mathrm{G}_{\mathrm{C} 4}\right) / 2$ respectively. The dashed line in the figure is the degree of significance of the correlation coefficient. When the number of data was $n=144$, the dashed green value was 0.319 and $\mathrm{p}=10^{-4}$, the dashed blue value was 0.271 and $\mathrm{p}=10^{-3}$, and the dashed black value was 0.214 and $\mathrm{p}=10^{-2}$. In all cases, we saw that the correlation coefficient had the maximum value when $\mathrm{N}=1$. Next, when $\mathrm{N}=$ 15, only Figure $8(\mathrm{c})$ had a correlation coefficient of more than 0.2 , which was significant and unlike the others.

Figures 9(a)-(d) show the correlation coefficient between the gas concentration of the summer data $(n=132)$ and the periodic approximation curve. Figures $9(a)-(d)$ are the results of $\left(G_{E 1}+G_{E 2}\right) / 2,\left(G_{E 3}+\right.$ $\left.\mathrm{G}_{\mathrm{E} 4}\right) / 2,\left(\mathrm{G}_{\mathrm{C} 1}+\mathrm{G}_{\mathrm{C} 2}\right) / 2,\left(\mathrm{G}_{\mathrm{C} 3}+\mathrm{G}_{\mathrm{C} 4}\right) / 2$ respectively. The dashed line in the figure is the degree of significance of the correlation coefficient. When the number of data was $n=132$, the dashed green value was 0.333 and $\mathrm{p}=10^{-4}$, the dashed blue value was 0.283 and $\mathrm{p}=10^{-3}$, and the dashed black value was 0.223 and $\mathrm{p}=10^{-2}$. In all cases, we saw that the changes were qualitatively the same.

Figures $10(a)-(d)$ are the results from analyzing seasonal changes focusing on a specific number of cycles $\mathrm{N}, \mathrm{N}=1,3,4$, and 15, respectively. The horizontal axis is the period shown in Table 1 and represents from winter to autumn. The features of the four graphs are summarized below.

When $N=1$, Figure $10(\mathrm{a}): 1)$ In winter, the correlation coefficient was 0.2 or less only for $\left(\mathrm{G}_{\mathrm{C} 1}+\right.$ $\left.\mathrm{G}_{\mathrm{C} 2}\right) / 2$, and 0.2 or more for the others. 2) In spring, the correlation coefficient of $\left(\mathrm{G}_{\mathrm{C} 1}+\mathrm{G}_{\mathrm{C} 2}\right) / 2$ was the largest, and the difference from the value of the pair $\left(\mathrm{G}_{\mathrm{E} 1}+\mathrm{G}_{\mathrm{E} 2}\right) / 2$ was large. 3) From summer to autumn, the correlation coefficient of the pair $\left(G_{\mathrm{E} 3}+G_{\mathrm{E} 4}\right) / 2$ and $\left(\mathrm{G}_{\mathrm{C} 3}+\mathrm{G}_{\mathrm{C} 4}\right) / 2$ decreased. However, the pair $\left(\mathrm{G}_{\mathrm{E} 1}+\right.$ $\left.\mathrm{G}_{\mathrm{E} 2}\right) / 2$ and $\left(\mathrm{G}_{\mathrm{C} 1}+\mathrm{G}_{\mathrm{C} 2}\right) / 2$ showed the opposite change, and the difference between $\left(\mathrm{G}_{\mathrm{E} 1}+\mathrm{G}_{\mathrm{E} 2}\right) / 2$ and $\left(\mathrm{G}_{\mathrm{C} 1}+\right.$ $\left.\mathrm{G}_{\mathrm{C} 2}\right) / 2$ was large in autumn. 4) The correlation coefficient had a minimum value of 0.2 or less in spring and a maximum value of 0.2 or more in summer or autumn.

When $N=3$, Figure 10(b): 1) The correlation coefficient of the pair $\left(\mathrm{G}_{\mathrm{E} 3}+\mathrm{G}_{\mathrm{E} 4}\right) / 2$ and $\left(\mathrm{G}_{\mathrm{C} 3}+\mathrm{G}_{\mathrm{C} 4}\right) / 2$ changed similarly throughout the seasons. However, the pair $\left(\mathrm{G}_{\mathrm{E} 1}+\mathrm{G}_{\mathrm{E} 2}\right) / 2$ and $\left(\mathrm{G}_{\mathrm{C1}}+\mathrm{G}_{\mathrm{C} 2}\right) / 2$ had a difference in summer. 2) In winter, the correlation coefficient was the maximum in all cases, and the correlation coefficient was 0.2 or more. 3) From spring to autumn, the pair $\left(G_{\mathrm{E} 1}+G_{\mathrm{E} 2}\right) / 2$ and $\left(\mathrm{G}_{\mathrm{C} 1}+\mathrm{G}_{\mathrm{C} 2}\right) / 2$ both showed a convex shape correlation coefficient, while the pair $\left(\mathrm{G}_{\mathrm{E} 3}+\mathrm{G}_{\mathrm{E} 4}\right) / 2$ and $\left(\mathrm{G}_{\mathrm{C} 3}+\mathrm{G}_{\mathrm{C} 4}\right) / 2$ both showed a concave shape correlation coefficient; there was a difference in the change between the pairs.

When $N=4$, Figure $10(\mathrm{c}): 1)$ The pair $\left(\mathrm{G}_{\mathrm{E} 1}+\mathrm{G}_{\mathrm{E} 2}\right) / 2$ and $\left(\mathrm{G}_{\mathrm{C} 1}+\mathrm{G}_{\mathrm{C} 2}\right) / 2$ showed almost equal changes, and no peculiarity for $\left(\mathrm{G}_{\mathrm{C} 1}+\mathrm{G}_{\mathrm{C} 2}\right) / 2$ was seen. 2) In spring, the correlation coefficient was the maximum in all cases, and the correlation coefficient was 0.2 or more. 3) From summer to autumn, there was a difference between the pair $\left(\mathrm{G}_{\mathrm{E} 1}+\mathrm{G}_{\mathrm{E} 2}\right) / 2$ and $\left(\mathrm{G}_{\mathrm{C} 1}+\mathrm{G}_{\mathrm{C} 2}\right) / 2$ and the pair $\left(\mathrm{G}_{\mathrm{E} 3}+\mathrm{G}_{\mathrm{E} 4}\right) / 2$ and $\left(\mathrm{G}_{\mathrm{C} 3}+\mathrm{G}_{\mathrm{C} 4}\right) / 2$. 


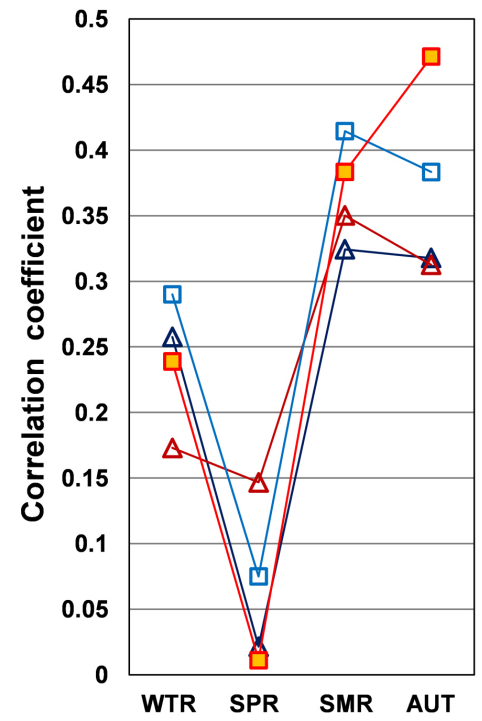

(a)

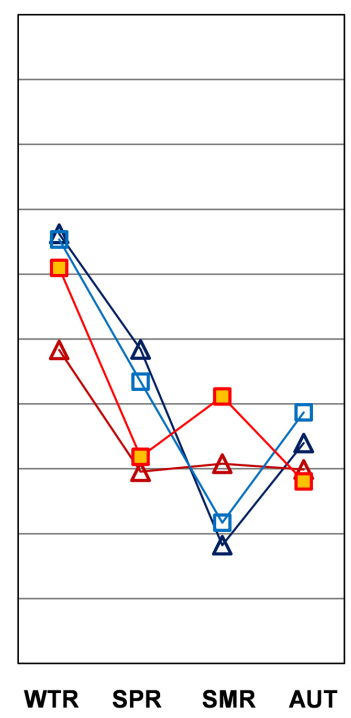

(b)

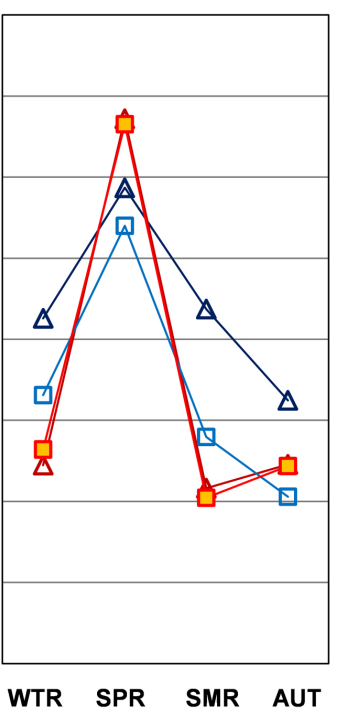

(c)

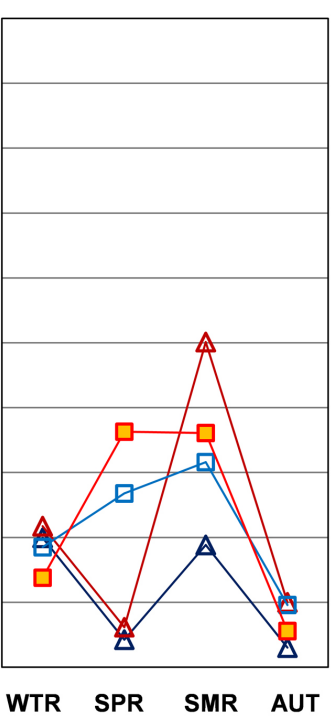

(d)

Figure 10. Seasonal change in correlation coefficient. (a) $N=1$. (b) $N=3$. (c) $N=4$. (d) $N=15$. The filled red square: $\left(G_{E 1}+G_{E 2}\right) / 2$. The open blue square: $\left(G_{E 3}+G_{E 4}\right) / 2$. The open dark red triangle: $\left(G_{C 1}\right.$ $\left.+\mathrm{G}_{\mathrm{C} 2}\right) / 2$. The open dark blue triangle: $\left(\mathrm{G}_{\mathrm{C} 3}+\mathrm{G}_{\mathrm{C} 4}\right) / 2$.

When $N=15$, Figure $10(\mathrm{~d}): 1$ ) In summer, only $\left(\mathrm{G}_{\mathrm{C} 1}+\mathrm{G}_{\mathrm{C} 2}\right) / 2$ had a correlation coefficient of 0.2 or more. 2) Differences in change were seen between the experimental and the control samples. There were no other distinct features.

\section{DISCUSSION}

There was entanglement between the experimental and control samples of the biosensors made from cucumber fruit sections. This entanglement was found to be due to the abnormal reaction of the gas concentrations of the control samples $\mathrm{G}_{\mathrm{C} 1}$ and $\mathrm{G}_{\mathrm{C} 2}$ at the calibration control point $8 \mathrm{~m}$ away via comparison to the experimental samples $G_{\mathrm{E} 1}$ and $\mathrm{G}_{\mathrm{E} 2}$ at the PS apex that were affected by the potential power of the PS. Then, the question remains whether the influence of the potential power of the PS apex on $G_{\mathrm{E} 1}$ and $\mathrm{G}_{\mathrm{E} 2}$ can be detected. One way to answer this question is to compare $\left(G_{\mathrm{E} 1}+G_{\mathrm{E} 2}\right) / 2$ with $\left(\mathrm{G}_{\mathrm{E} 3}+\mathrm{G}_{\mathrm{E} 4}\right) / 2$. The results showed no significant difference between $\left(G_{\mathrm{E} 1}+G_{\mathrm{E} 2}\right) / 2$ and $\left(\mathrm{G}_{\mathrm{E} 3}+\mathrm{G}_{\mathrm{E} 4}\right) / 2$ (Figure 4). Therefore, we concluded that the pyramid effects on $\left(\mathrm{G}_{\mathrm{E} 1}+\mathrm{G}_{\mathrm{E} 2}\right) / 2$ cannot be directly detected by the analysis of the average gas concentration. On the other hand, in Figure 10, $\left(\mathrm{G}_{\mathrm{E} 1}+\mathrm{G}_{\mathrm{E} 2}\right) / 2$ and $\left(\mathrm{G}_{\mathrm{E} 3}+\mathrm{G}_{\mathrm{E} 4}\right) / 2$ were compared in terms of the seasonal change of the correlation coefficient between the gas concentration and its periodic approximation curve. And we confirmed the pyramid effects on $\left(\mathrm{G}_{\mathrm{E} 1}+\mathrm{G}_{\mathrm{E} 2}\right) / 2$. Here, we detected the pyramid effects without using the psi index. Next, we considered the reason why we could not detect the entanglement between biosensors by using the psi index [10]. In Equation (2), the gas concentrations of the experimental samples are divided by the gas concentrations of the control samples in order to calculate $\Psi_{1}$ and $\Psi_{2}$, which are the psi indices for the biosensors placed at the PS apex. In other words, the gas concentrations of the control samples are reflected in the psi indices from the beginning. Therefore, when there is an entanglement effect on $\mathrm{G}_{\mathrm{C} 1}$ and $\mathrm{G}_{\mathrm{C} 2}$, the psi indices represent the pyramid effects that include not only the potential power effect on $\mathrm{G}_{\mathrm{E} 1}$ and $\mathrm{G}_{\mathrm{E} 2}$ but also the entanglement effect on $\mathrm{G}_{\mathrm{C} 1}$ and $\mathrm{G}_{\mathrm{C} 2}$.

$$
\begin{aligned}
& \Psi_{1}=100 \ln \left(\mathrm{G}_{\mathrm{E} 1} / \mathrm{G}_{\mathrm{C} 1}\right), \\
& \Psi_{2}=100 \ln \left(\mathrm{G}_{\mathrm{E} 2} / \mathrm{G}_{\mathrm{C} 2}\right) .
\end{aligned}
$$

Investigation of the cause of the entanglement between biosensors prepared by cutting cucumber 
fruits is a future research subject. Through our experiments to date, we have discovered the entanglement between biosensors due to the pyramid effects. A recent study on the quantum entanglement reported that the interaction between entangled photons and psychological effects was detected with statistical significance [19]. We consider that there is a close relationship between the pyramid effects and the psychological effect, thus, the pyramid effects and the entanglement phenomenon will continue to be an important research subject.

\section{CONCLUSIONS}

In this paper, we found that the periodicity of diurnal fluctuations in the concentration of gas emitted from biosensors was changed by the entanglement between biosensors due to the pyramid effects. In addition, as a result of analyzing the data by dividing it into four seasons of winter, spring, summer, and autumn, we clarified the seasonal dependence of the periodicity of diurnal variation due to entanglement. In conclusion, we reaffirmed the existence of the entanglement between biosensors due to the pyramid effects by a phenomenon different from Part IV of the paper series, Potential Power of the Pyramidal Structure.

We expect that our research results will be widely accepted in the future and will become the foundation for a new research field in science, with a wide range of applications.

\section{CONFLICTS OF INTEREST}

The authors declare no conflicts of interest regarding the publication of this paper.

\section{REFERENCES}

1. Ostrander, S. and Schroeder, L. (1970) Psychic Discoveries behind the Iron Curtain. Prentice-Hall, Inc., Hoboken.

2. Grandics, P. (2009) The Pyramid Electric Generator. Infinite Energy, 84, 1-4. https://www.researchgate.net/publication/255709759

3. Rubik, B. and Jabs, H. (2016) Interactions of Pyramidal Structures with Energy and Consciousness. The Journal of Natural and Social Philosophy, 12, 259-275. https://www.researchgate.net/publication/309407219

4. Takagi, O., Sakamoto, M., Kokubo, H., Yoichi, H., Kawano, K. and Yamamoto, M. (2013) Meditator's Non-Contact Effect on Cucumbers. International Journal of Physical Sciences, 8, 647-651. https://doi.org/10.5897/IJPS2012.3800

5. Takagi, O., Sakamoto, M., Yoichi, H., Kokubo, H., Kawano, K. and Yamamoto, M. (2015) Discovery of an Anomalous Non-Contact Effect with a Pyramidal Structure. International Journal of Sciences, 4, 42-51. https://doi.org/10.18483/ijSci.714

6. Takagi, O., Sakamoto, M., Yoichi, H., Kokubo, H., Kawano, K. and Yamamoto, M. (2016) An Unknown Force Awakened by a Pyramidal Structure. International Journal of Sciences, 5, 45-56. https://doi.org/10.18483/ijSci.1038

7. Takagi, O., Sakamoto, M., Yoichi, H., Kokubo, H., Kawano, K. and Yamamoto, M. (2018) Discovery of Seasonal Dependence of Bio-Reaction Rhythm with Cucumbers. International Journal of Science and Research Methodology, 9, 163-175. https://www.researchgate.net/publication/331917254

8. Takagi, O., Sakamoto, M., Yoichi, H., Kokubo, H., Kawano, K. and Yamamoto, M. (2018) Relationship between Gas Concentration Emitted from Cut Cucumber Cross Sections and Growth Axis. International Journal of Science and Research Methodology, 9, 153-167. https://www.researchgate.net/publication/331917255

9. Takagi, O., Sakamoto, M., Yoichi, H., Kokubo, H., Kawano, K. and Yamamoto, M. (2019) Discovery of an Unexplained Long-Distance Effect Caused by the Association between a Pyramidal Structure and Human Unconsciousness. Journal of International Society of Life Information Science, 37, 4-16. 


\section{https://doi.org/10.18936/islis.37.1_4}

10. Takagi, O., Sakamoto, M., Yoichi, H., Kawano, K. and Yamamoto, M. (2019) Potential Power of the Pyramidal Structure. Natural Science, 11, 257-266. https://doi.org/10.4236/ns.2019.118026

11. Takagi, O., Sakamoto, M., Yoichi, H., Kawano, K. and Yamamoto, M. (2020) Potential Power of the Pyramidal Structure II. Natural Science, 12, 248-272. https://doi.org/10.4236/ns.2020.125022

12. Takagi, O., Sakamoto, M., Yoichi, H., Kawano, K. and Yamamoto, M. (2020) Potential Power of the Pyramidal Structure III: Discovery of Pyramid Effects with and without Seasonal Variation. Natural Science, 12, 743-753. https://doi.org/10.4236/ns.2020.1212066

13. Takagi, O., Sakamoto, M., Kawano, K. and Yamamoto, M. (2021) Potential Power of the Pyramidal Structure IV: Discovery of Entanglement Due to Pyramid Effects. Natural Science, 13, 258-272. https://doi.org/10.4236/ns.2021.137022

14. Takagi, O., Sakamoto, M., Yoichi, H., Kokubo, H., Kawano, K. and Yamamoto, M. (2016) Necessary Condition of an Anomalous Phenomenon Discovered by a Pyramidal Structure. Journal of International Society of Life Information Science, 34, 154-157. https://doi.org/10.18936/islis.34.2_154

15. Takagi, O., Sakamoto, M., Yoichi, H., Kokubo, H., Kawano, K. and Yamamoto, M. (2019) Discovery from the Experiment on the Unexplained Functions of the Pyramidal Structure-The Phenomenon Caused by the Personal Relationship. Journal of International Society of Life Information Science, 37, 60-65. https://doi.org/10.18936/islis.37.1_60

16. Takagi, O., Sakamoto, M., Yoichi, H., Kawano, K. and Yamamoto, M. (2020) Scientific Elucidation of Pyramid Power: I. Journal of International Society of Life Information Science, 38, 130-145. https://doi.org/10.18936/islis.38.2_130

17. Takagi, O., Sakamoto, M., Yoichi, H., Kawano, K. and Yamamoto, M. (2020) Meditator's Non-Contact Effect on Cucumbers. In: Rafatullah, M., Ed., Theory and Applications of Physical Science, Vol. 3, Book Publisher International, London, Chapter 4. https://doi.org/10.9734/bpi/taps/v3

18. Kokubo, H., Takagi, O. and Koyama, S. (2010) Application of a Gas Measurement Method-Measurement of Ki Fields and Non-Contact Healing. Journal of International Society of Life Information Science, 28, 95-103. https://doi.org/10.18936/islis.28.1_95

19. Radin, D., Bancel, P.A. and Delorme, A. (2021) Psychophysical Interactions with Entangled Photons: Five Exploratory Studies. Journal of Anomalous Experience and Cognition, 1, 9-54. https://doi.org/10.31156/jaex.23392 